\title{
Horizontal gene transfer in the human gastrointestinal tract: potential spread of antibiotic resistance genes
}

This article was published in the following Dove Press journal:

Infection and Drug Resistance

20 June 2014

Number of times this article has been viewed

Jennifer R Huddleston

Biology Department, Abilene

Christian University, Abilene, TX, USA

Correspondence: Jennifer R Huddleston Biology Department, Abilene Christian University, ACU Box 27868, Abilene,

TX 79699, USA

$\mathrm{Tel}+\mathrm{I} 3256742010$

Fax +I 3256742009

Email jennifer.huddleston@acu.edu

\begin{abstract}
Bacterial infections are becoming increasingly difficult to treat due to widespread antibiotic resistance among pathogens. This review aims to give an overview of the major horizontal transfer mechanisms and their evolution and then demonstrate the human lower gastrointestinal tract as an environment in which horizontal gene transfer of resistance determinants occurs. Finally, implications for antibiotic usage and the development of resistant infections and persistence of antibiotic resistance genes in populations as a result of horizontal gene transfer in the large intestine will be discussed.
\end{abstract}

Keywords: gut microbiome, conjugation, natural transformation, transduction

\section{Introduction}

The emergence of antibiotic resistant infections is considered to be a major global health issue. ${ }^{1}$ It is feared that the golden age of antibiotic therapy is coming to an end, and that we will soon return to a pre-antibiotic era, where there are limited successful treatments for infectious diseases caused by bacteria. These resistant infections are costly to society in economic impact as well as in the morbidity and mortality of affected individuals. Taking into account just methicillin-resistant Staphylococcus aureus and third-generation cephalosporin-resistant Escherichia coli infections alone, each year there are thousands of deaths, exceedingly more infections, and millions of international dollars spent on health care costs. ${ }^{2}$ Even though infectious diseases still remain a leading cause of death worldwide, ${ }^{3}$ antibiotic development by pharmaceutical companies has decreased dramatically, only contributing to about $0.2 \%$ of new drug development. ${ }^{4}$ Evolution of antibiotic resistance continues, especially that of multidrug resistant strains, complicating treatment options. ${ }^{1}$

Bacterial populations susceptible to antibiotics become resistant either through genetic mutation or through horizontal transfer and expression of resistance genes from other strains, either distantly or closely related. The human gastrointestinal tract provides an ideal combination of factors for antibiotic resistance genes to arise and spread through bacterial populations. One of these factors is high cell density. Other factors favoring spread of resistant infections include antibiotic exposure and subsequent selection followed by the innate ability for gene transfer through a variety of different mechanisms.

The aim of this review is to provide a brief overview of the bacterial processes that facilitate horizontal gene transfer, and to propose how this phenomenon may be taking place in the lower human gastrointestinal tract, specifically the large intestine, 
intensifying the antibiotic resistance crisis we are currently facing and setting the stage for future resistant infections.

\section{Mechanisms and evolution of horizontal gene transfer}

The three major mechanisms by which bacteria transfer genes horizontally are conjugation, natural transformation, and transduction. Conjugation is the most studied mechanism of horizontal gene transfer in the human intestine or otherwise. ${ }^{5-7}$ Conjugation is the transfer of DNA fragments that can be very small, up to large chromosomes. The general order of the events of conjugation is a) cell-to-cell contact, b) mating pair formation, and finally c) transfer of plasmid DNA through a conjugative pilus. The conjugative pilus is considered to be machinery of the Type IV secretion system. ${ }^{8}$ The genes for conjugative machinery are encoded by autonomously replicating plasmids or by integrative conjugative elements in the chromosome. ${ }^{9}$

Conjugation requires cell-to-cell contact, usually via a pilus or pore that forms a channel that allows for the passage of plasmids. Generally, plasmids are covalently closed, circular molecules of DNA that replicate independently from the host chromosome. Some plasmids are conjugative, that is self-transmissible, while others are not. Conjugative plasmids harbor genes for the transfer machinery. These nonconjugative plasmids are mobilizable if they can be transferred through conjugation when a helper self-transmissible plasmid is present. ${ }^{10}$ An in-depth model for the evolution of the mechanisms of conjugation has recently been elucidated, and the reader is referred to Guglielmini et al for further details. ${ }^{11}$

The role of conjugation in horizontal gene transfer is further complicated by the fact that other mobile genetic elements besides plasmids can be transferred by conjugative machinery. Conjugative transposons are transposons which excise themselves from covalently closed circular DNA, such as a plasmid or chromosome, and integrate into another location in the same genome or are transferred by conjugation and then integrated into a different genome. These elements can also mobilize non conjugative plasmids or other DNA sequences in a cell and transfer them. ${ }^{12}$ Another level of complexity is added when other mobile genetic elements such as integrons or integrating conjugative elements (ICE) are considered in tandem with plasmids and conjugative transposons. ${ }^{13}$ Integrons are mobile genetic elements that encode integrase and are capable of site-specific recombination and typically carry antibiotic resistance genes. ${ }^{14} \mathrm{ICE}$ are transferred through cell-to-cell contact and can integrate into the chromosome of the recipient. SXT, an approximately $100 \mathrm{~kb}$ fragment of DNA, is one of the most widely studied of these elements and confers resistance to chloramphenicol, sulfamethoxazole, and trimethoprim and has both plasmid and phage sequences. ${ }^{9,15}$ Virtually any gene in intestinal bacteria can acquire the ability to be mobilized and transferred via a mobile genetic element. ${ }^{16}$

The main mechanism of horizontal transfer of plasmids is through conjugation. ${ }^{17}$ However, natural transformation does allow for the uptake of plasmid DNA as well as chromosomal DNA. Because of this, it is widely accepted that natural transformation is a major mechanism in the evolution of microbes. However, it is still unclear as to how and why the process itself evolved. Natural transformation is the process whereby bacterial cells take up free DNA from the environment and incorporate it into their genomes. There are over 80 known different species of naturally transformable bacteria, which includes members from different lineages including photolithotrophs, chemolithotrophs, heterotrophs, and methylotrophs. ${ }^{18,19}$ At least a dozen of these strains are pathogens which have been isolated from the clinical setting. ${ }^{18}$ When evaluating bacterial or archaeal strains as naturally transformable, laboratory conditions known to induce competence are used. There are unquestionably many more strains that are naturally transformable, but have not been designated as such, because it is still unknown what environmental factor or combinations of factors trigger competence development. The evolutionary origin of natural transformation is unclear because the process is widely distributed over the major clades of bacteria and yet members of the same genus or even species can differ in their ability to be naturally transformed. This suggests that either there is a common origin for transformation that has been lost many times or that it has arisen independently on multiple occasions. ${ }^{20}$

The overall process of natural genetic transformation can be broken down into six major steps. ${ }^{18}$ They are a) DNA is released from donor cells, b) DNA is dispersed, c) DNA persists in the environment, d) recipient cells become competent for DNA uptake, e) competent cells interact with and take up the DNA, incorporating it into the genome either through homologous or illegitimate recombination, and finally f) genes encoded on the donor DNA are expressed in the recipient cells. ${ }^{18}$ In the former three steps, the donor cell need not be alive or even in close proximity to the recipient, whereas the recipient cell is actively involved in the latter three steps.

There are five models explaining reasons why bacteria take up DNA from the environment. With the exception of 
Neisseria gonorrhea, ${ }^{21}$ all known transformable bacteria must be induced to competence. Competence is the physiological state that allows for uptake of DNA into a bacterial cell. During competence development, genes for protein components of the uptake machinery are expressed. There are many triggers for competence development, which also makes it difficult to understand the evolutionary origins of the process.

The first model suggests that DNA is taken up into the bacterial cell to be used as a nutrient source. ${ }^{22}$ This model is supported by studies that show some bacterial strains become competent to take up DNA under nutrient-limited conditions. ${ }^{23}$ Many bacterial species, such as Gallibacterium anatis, ${ }^{24}$ Haemophilus influenza, ${ }^{25}$ and Aeromonas salmonicida ${ }^{26}$ are induced to competence in vitro by transferring the cultures from a rich medium to a starvation medium. More specifically, H. influenzae becomes competent as a result of purine starvation. $^{27}$

The second model explaining the evolutionary origins of competence development and natural transformation is that natural transformation evolved so that transformed DNA molecules could serve as templates for DNA repair. Bacillus subtilis cells exposed to ultraviolet light have greater survivorship when they are treated with DNA after damage than if they are treated with DNA before damage. The added DNA presumably serves as a template in recombinational repair. ${ }^{28}$ Competence, specifically the com regulon, can be induced in Streptococcus pneumoniae upon exposure to mitomycin C, a DNA-damaging agent. ${ }^{29}$

A third model is that natural transformation evolved to allow the cell to purposely obtain novel genetic information to increase genetic diversity in order to respond more favorably to natural selection. ${ }^{30}$ However, a study on transformability in Acinetobacter baylyi revealed that both competent strains and noncompetent strains adapted to laboratory conditions at the same rate. ${ }^{31}$ Competence did not confer any discernible advantage, and the competent lineages even evolved a lower level of transformability under laboratory conditions. Engelstädter and Moradigaravand recently proposed a complementary model in which competence evolved because it allows bacterial cells to take up DNA from the environment that has persisted for an indefinite period of time to incorporate genes into genomes in order that the cell may revert to a prior genetic state. ${ }^{32}$

The fourth model is that natural transformation evolved and is maintained because of episodic stressful conditions that may indirectly select for non-growing competent cells. ${ }^{33}$ Competent populations of cells, like Bacillus subtilis, do not grow for several hours. ${ }^{34}$ This is considered to be a "persister" state. The persister state was first recognized in 1944 in surviving Staphylococcus cells that were treated with penicillin. These cells survived because they were not growing and unaffected by the antibiotic, not because they were mutants with altered antibiotic targets. ${ }^{35}$ These cells are now considered to be tolerant to antibiotics instead of resistant to them. ${ }^{36}$ Episodic selection of persister cells occurs when the cell population experiences stressful conditions that kill the growing cells at a higher rate than the non-growing persister cells. If these persister cells are also competent as some are, then natural transformation ability is also indirectly selected by the stress. ${ }^{33}$ This hypothesis has been supported using antibiotics (penicillin-G) as the episodic selection in populations of B. subtilis where the competent cells had better survivability than the non-competent mutants. ${ }^{33}$

The fifth, and final, model posits that natural transformation is an unintended consequence of the type IV pili actions of twitching motility and cell adhesion. ${ }^{37}$ Type IV pili are known to take up free DNA during natural transformation. ${ }^{38,39}$ As the cells move across surfaces using their type IV pili for twitching motility, it is possible that they accidentally bind DNA at PilC, the tip of the pilus. As the pilus retracts, the bound DNA blocks the PilQ pore present in the outer membrane and passes through it after one strand is degraded by nucleases. In this model, environmental stress triggers the SOS response (an error-prone DNA repair system), inducing the expression of type IV pili so that the cell can move using twitching motility to a more favorable environment. Free DNA is bound and taken up by the cell as a consequence of the active type IV pili. ${ }^{37}$ In this model, natural transformation ability is accidental, although it can be beneficial when the cell is able to use the new DNA as a nutrient source or as a template for genome repair. ${ }^{37}$ Whatever the biological reason for the uptake, one consequence of transformation is a changed genotype of the recipient cell. Transformation is widespread among microorganisms and has a lasting impact on bacterial genomes that is difficult, if not impossible, to assess. ${ }^{40}$

Transduction is another mechanism of horizontal gene transfer that has shaped the evolution of bacterial genomes. The abundance of information about antibiotic resistance gene transfer via bacteriophages is limited when compared to natural transformation and conjugation. However, the role of bacteriophages in transducing antibiotic resistance genes is now becoming clearer. Bacteriophages are viruses that infect bacteria and are considered to be temperate if they integrate into the host genome and become prophages until environmental conditions trigger their lytic growth. ${ }^{41}$ This 
state can last indefinitely and can confer resistance to infection by bacteriophages of the same group. ${ }^{41}$

Transduction occurs when a bacteriophage that has previously replicated in another bacterial cell packages a portion of the host genome (donor) into the phage head and transfers the genes to another (recipient) bacterial cell. Transduction is thought to be an unevolved process that occurs as a consequence of mistakes in excision of bacteriophage DNA from the donor genome. Transduction can be classified as either specialized or generalized. Specialized transduction occurs when only bacterial DNA adjacent to the attachment site of a temperate bacteriophage, as in $\lambda$ in $E$. coli, is accidentally packaged into the bacteriophage and subsequently transferred to a recipient cell. Generalized transduction occurs when any gene from a host is randomly packaged along with viral DNA into a bacteriophage head, such as occurs in P22 of Salmonella, and then transferred to a new recipient. The donor strain and the recipient strain need not be in close proximity in either geographical location or time to one another, as bacteriophages can persist in the environment for varying time periods. ${ }^{42}$ Virtually any DNA sequence, including antibiotic resistance, found in a bacterial genome can be transferred. ${ }^{43}$ This includes chromosomal sequences and mobile genetic elements like plasmids, transposons, and insertion elements. ${ }^{44}$

Transduction as a significant mechanism of horizontal gene transfer in naturally occurring environments has traditionally been underestimated. A metagenomic analysis of viromes suggests that functional bacterial genes of all types exist in up to $50 \%$ to $60 \%$ of bacteriophages and that these particles can serve as a reservoir for genes in a diversity of environments and also a mechanism for their transfer among bacteria. ${ }^{45}$ Transduction as an important mechanism of horizontal gene transfer has gained support with significant studies showing that antibiotic resistance genes are found in abundance in phage particles in nature. ${ }^{42}$ Transduction has only recently been considered as playing a significant role in the transfer of antibiotic resistance among potential pathogens as demonstrated from Enterococcus gallinarum to Enterococcus faecalis during in vitro experiments. ${ }^{46}$ Other in vitro experiments with Salmonella transducing bacteriophages demonstrated that ampicillin, chloramphenicol, and tetracycline resistance genes could be transduced. ${ }^{43}$

\section{Role of horizontal gene transfer in the spread of antibiotic resistance genes in the large intestine}

Conjugation, natural transformation, and transduction have served as important mechanisms in the evolution of bacteria.
However, there is evidence that these mechanisms play a role in evolution that is currently occurring in the large intestine under the selective pressure of antibiotics. The most common mechanism of horizontal gene transfer in other natural environments is thought to be by plasmids through conjugation. ${ }^{17}$ It stands to reason that this is also true for the gastrointestinal tract.

The lower gastrointestinal tract is the largest microbial community in the human host, consisting of up to $10^{14}$ individual bacterial cells of over 500 species from nine bacterial divisions, including Actinobacteria, Bacteroidetes, Cyanobacteria, Firmicutes, Fusobacteria, Proteobacteria, Spirochaeates, Verrucomicrobia, and VadinBE97. ${ }^{47,48,49}$ Biofilms are found in the human intestinal tract and are thought to be ideal environments for horizontal gene transfer because they allow for high bacterial density and physical protection for the cells. The biofilm environment supports the cell-to-cell contact needed for conjugation to occur. ${ }^{50,51} \mathrm{E}$. coli cells are found as coccoid cells embedded in the mucosal layer of the large intestine. ${ }^{52,53}$ As a side note, populations of Streptococcus pyogenes growing in laboratory biofilms become naturally transformable. ${ }^{54}$ These biofilms consist of many species and have a greater resistance to antibiotics than their free-living counterparts. ${ }^{55,56}$

Salyers et $\mathrm{al}^{57}$ proposed the resistance gene reservoir hypothesis in which bacteria of the human gastrointestinal tract serve as a reservoir for antibiotic resistance genes that can be transferred to other resident intestinal bacteria or transient bacteria that pass through, but do not colonize, the large intestine for a significant period of time. Several recent studies have demonstrated the magnitude of antibiotic resistance gene reservoir in the human intestinal tract. The most current version of the Antibiotic Resistance Genes Database (ARDB) lists over 23,000 known gene and protein sequences for at least 240 different antibiotics (version 1.1). ${ }^{58} \mathrm{~A}$ study comparing the gut metagenomes from 275 individuals to the sequences deposited in the ARDB database showed resistance to 53 antibiotics. The study also found multiple antibiotic resistance genes on contigs with integrase and transposase, indicating the possibility that these clusters are part of mobile genetic elements, such as conjugative transposons. Furthermore, 97\% of the gut metagenomes harbored resistance genes to tetracycline, $95 \%$ to bacitracin, and $95 \%$ to tetracycline. ${ }^{59}$ Another metagenome analysis evaluated the gut microbiome from 162 individuals (encompassing 4.1 million genes) and found 1,093 antibiotic resistance genes. ${ }^{60} \mathrm{~A}$ single erythromycin gene type, $\operatorname{erm} B$, was found in all but one of the samples. A gene, b12e_cfxa, conferring 
resistance to cephalosporin and $b a c A$ (recently renamed as upp $P$ ), conferring resistance to bacitracin, and $v a n R G$, conferring resistance to vancomycin, were also found at high relative abundance in the samples. ${ }^{61}$ The human intestinal tract is a reservoir for more antibiotic resistance genes than any other studied natural environment, such as soil, marine, or lake environments. ${ }^{61,60}$

Forslund et al compared metagenomes analysis from 252 fecal samples from individuals from Spain, Denmark, and the United States. ${ }^{62}$ The antibiotic resistance genes were more abundant in all metagenomes for those antibiotics that have been used in the clinical setting longer and for those that are approved by the national governments for use in livestock than the antibiotics introduced later and not used in animals. In fact, resistance genes for antibiotics approved for use in livestock are the most abundant resistance genes in the human gut microbiome. ${ }^{62}$ This evidence supports the "farm-to-fork" hypothesis that the non-therapeutic use of antibiotics in animal husbandry leads to increased antibiotic resistance in humans through consumption of affected food or water. ${ }^{63,64}$ Antibiotics can pass into the human gastrointestinal tract through the consumption of undercooked or precooked meat exposing the resident microflora and the transient bacterial cells to the effects of the antibiotics.

Specifically, a source of antibiotic resistance genes in the human large intestine is the lactic acid bacteria. These bacteria convert fermentable carbohydrates into lactic acid. They are typically Gram-positive, catalase-negative, have low C + G content, and include Enterococcus, Lactobacillus, Lactococcus, Leuconostoc, Pediococcus, and Streptococcus. ${ }^{65}$ They are used in the production of dairy products such as yogurt, buttermilk, and some cheeses as well as in the production of sausage, hams, and wine. ${ }^{65}$ Lactic acid bacteria colonize the human large intestine but can cause opportunistic infections in immunocompromised patients. ${ }^{65}$ The US Food and Drug Administration (FDA) declared lactic acid bacteria as "Generally Regarded As Safe" (GRAS) in terms of ingestion of these microbes, but there are new questions as to whether these strains may serve as a source of antibiotic resistance genes. Atypical isolates resistant to erythromycin and tetracycline have been found ${ }^{66}$, as well as strains harboring plasmids encoding resistance to chloramphenicol that were derived from staphylococcal sequences and a tetracycline gene that is identical to one found in Listeria monocytogenes. ${ }^{67}$

Further in vivo and in vitro studies into transmissibility of genes among lactobacilli have demonstrated that, in the absence of selection, tetracycline resistance is not widely transferred. ${ }^{68,69}$ However, in an in vivo study, an Enterococcus faecium isolate from animal origin transferred vanA, a gene for vancomycin-resistance, to a vancomycin-susceptible E. faecium of human origin in the intestines of half $(3 / 6)$ of the human volunteers. ${ }^{70}$ The donor strain from animal origin did not persist and disappeared within two weeks of inoculation. This lends further support to the "farm-to-fork" hypothesis in which transient strains can be ingested in food and then transfer antibiotic resistance to commensals in the human intestine. ${ }^{70}$

Another similar in vivo study where human volunteers ingested $E$. coli shows similar results. In this case, instead of the transfer of genes between the two administered strains in the gastrointestinal tract as the experiments were designed, sulfonamide and ampicillin resistances were transferred on a conjugative plasmid from the indigenous $E$. coli to the administered E. coli. ${ }^{71}$

Reports where horizontal gene transfer was demonstrated to have occurred in the lower gastrointestinal tract are becoming more frequent. An analysis of a nosocomial outbreak of Enterobacter cloacae revealed that there was probable conjugal transfer of an OXA-48 (carbapenem-resistance) encoding plasmid from E. cloacae to other members of Enterobacteriaceae in the intestines of a patient, which was then spread to other patients. ${ }^{72}$ Another report showed that an $E$. coli donor strain transferred ampicillin resistance on a plasmid to another $E$. coli strain in the intestines of an infant. It is presumed that treatment with ampicillin for a urinary tract infection provided the selection needed in order for the donor density to increase and favor the transfer of the plasmid to the recipient strain. ${ }^{73}$

Another case study reported the presumable transfer of a multidrug resistance plasmid from Klebsiella pneumoniae to $E$. coli in the gastrointestinal tract of a patient. Before treatment with ertapenem, metronidazole, colistin, and vancomycin, no carbapenem-resistant $E$. coli could be isolated from the patient, but after treatment a resistant strain was found. This resistant E. coli had the Klebsiella pneumoniae plasmid, $b l a_{\mathrm{KPC}-3}$, which conferred resistance to cephalosporins, monobactams, and carbapenems. Again, antibiotic treatment is thought to have triggered the transfer and maintained the selection of the resistance plasmid. ${ }^{74}$

Other studies have demonstrated the conjugal transfer of resistance plasmids in the gastrointestinal tracts of animal models. A plasmid encoding resistance to $\beta$-lactams, aminoglycosides, tetracyclines, sulfonamides, and phenicols was transferred from Serratia liquefaciens to E. coli in the intestinal tracts of gnotobiotic mice with human fecal flora. ${ }^{75}$ Gentamicin resistance was transferred from 
Enterococcus faecalis to E. coli, ${ }^{76}$ while aminoglycoside and macrolide resistance was transferred via conjugation among Enterococcus strains. ${ }^{77}$

The conjugation of plasmids encoding antibiotic resistance machinery has led to worldwide dissemination of these genes, particularly in Enterobacteriaceae. These plasmids can encode resistance to $\beta$-lactamases (CMY, DHA, GES, LAP, NDM, SHV, TEM), extended spectrum $\beta$-lactamases (CTX, VEB), metallo $\beta$-lactamases (IMP), carbapenemases (KPC, VIM); quinolone resistance (Qep, Qnr), aminoglycoside resistance (AAC, Arm, RmtB), tetracycline resistance (Tet), sulfonamide resistance (Sul), colistin resistance. They also encode the Cfr rRNA methyltransferase which confers resistance to phenicols, lincosamides, oxazolidinones, pleuromutilins, and streptogramin $\mathrm{A} . .^{78-82}$

A study evaluating fecal fosmid libraries for the presence of tetracycline resistance gene found a single individual to have distantly related bacteria harboring identical resistance sequences. The authors propose that this individual most likely acquired the genes through horizontal gene transfer in the gastrointestinal tract. ${ }^{83}$

An investigation by Shoemaker et al revealed that Bacteroides strains have undergone extensive horizontal gene transfer over the past 30 years leading to widespread resistance to tetracycline and erythromycin encoded by just a few identical determinants carried on conjugal elements. ${ }^{84}$ It is hypothesized that the human colon provides an environment in which Bacteroides can engage in horizontal gene transfer within the genus and across distantly related genera. ${ }^{84}$

Horizontal gene transfer in the large intestine occurs at levels that cannot be detected because of the complex nature of the microbial community structure both in diversity and in cell numbers. The physical and chemical conditions in this environment allow for natural transformation, conjugation, and transduction to occur. However, horizontal gene transfer through natural transformation may occur at greater frequencies than previously expected due to the presence of triggers of competence that we have not yet discovered. The importance of natural transformation in this environment, and possibly all environments, is underestimated.

\section{Implications for antibiotic usage and the development of resistant infections}

It has long been known that antibiotic resistance arises as a consequence of exposure to antibiotics. The resistant cells in a population have an advantage over sensitive cells when exposed to this strong selection. Therefore, the population becomes resistant to antibiotics. However, it is now known that antibiotics not only select for resistant populations through the clonal expansion of already-resistant cells, but they also create them by inducing the horizontal transfer of resistance genes.

Antibiotic exposure is a source of stress that can create stress-induced resistance among bacteria as part of the SOS response. The SOS response is an inducible DNA repair network, first discovered in E. coli by Radman in $1975 .{ }^{85}$ Under the response, mutations and genetic exchanges within the cell increase in order for damaged DNA to be repaired and the cell to survive. As a consequence of these genetic manipulations, any gene sequence, including those for antibiotic targets can be altered, providing the possibility for evolution of resistance ${ }^{86}$ Furthermore, antibiotics that cause double-stranded breaks, such as ciprofloxacin induce the SOS response. The SOS response is both induced by antibiotics and allows for antibiotic resistance to arise ${ }^{86}$ Chromosomal mutations accumulate rapidly which, as a consequence, confer resistance, as demonstrated by Streptococcus uberis and Pseudomonas aeruginosa gaining resistance to multiple antibiotics when exposed to sub-lethal concentrations of single antibiotics. ${ }^{87,88}$ In a study with Acinetobacter oleivorans, it was demonstrated that treatment with norfloxacin provided selection of resistant variants, induced genetic changes which resulted in a beneficial mutation in the molecular target of norfloxacin, gyrA, and also caused an upregulation of the SOS response. ${ }^{89}$

It is well established that antibiotic stress induces the SOS response, but for some of those bacterial strains that lack the response another mechanism is induced. Legionella pneumophila, a pathogen of human alveolar macrophages which lacks the SOS response, is induced to competence for natural genetic transformation by fluoroquinolones and other DNA-damaging antibiotics and chemicals. ${ }^{90}$ The same is true for the human pathogen $S$. pneumoniae, which uses competence as a general response to stress, and has been shown to become competent under exposure to aminoglycoside and fluoroquinolone antibiotics. ${ }^{29}$ Antibiotics can provide enough stress to induce competence in strains without the SOS response, and the environment of the gastrointestinal system is conducive to natural transformation. Presumably, DNA is present from recently lysed cells and could be protected from degradation by biofilms. Extracellular DNA is also a major constituent of most biofilms..$^{91}$ At this time it is still unknown if competence can be induced by antibiotics in other pathogenic strains that lack the SOS response, like 
Neisseria gonorrhoeae, Neisseria meningitides, and Campylobacter jejuni. ${ }^{92}$

When the SOS response is triggered, it directly induces the activation of prophages to lytic bacteriophages, which has consequences on both evolution and the ecology of the microflora of the gastrointestinal tract. ${ }^{93}$ For example, Burkholderia thailandensis (a soil microbe), in response to ciprofloxacin exposure, transcribed genes associated with the SOS response as well as those of a viable bacteriophage. ${ }^{94}$

A study analyzing the intestinal microflora of mice showed that antibiotic administration of ciprofloxacin and ampicillin creates stressful conditions for bacteria, inducing the SOS response, which increases the abundance of antibiotic resistance genes found within the phage particles. ${ }^{95}$ These phages can act as a reservoir of all types of genes in order to maintain the functional integrity of the intestinal microflora. Subsequent bacteriophage infection allows for the transduction of resistance genes. There is evidence that the favored life cycle of bacteriophages is lysogeny in the gastrointestinal tract. ${ }^{55}$ However, in the "community shuffling" model, the SOS response causes induction of prophages to bacteriophages resulting in the lysing of bacteria, which in turn causes dysbiosis. ${ }^{89,55}$ Dysbiosis is a disturbance in the normal intestinal microflora and a precursor to chronic diseases, such as Crohn's disease, ulcerative colitis, and irritable bowel syndrome. ${ }^{96,97}$ Higher abundance of bacteriophages has been found in gut wash samples of individuals with Crohn's disease compared to those without disease..$^{98}$ This suggests that induction by antibiotics may assist in the development of acute infections as well as in chronic diseases, but more research must be done in order to test this hypothesis.

Induction of the SOS response has other implications for the development of resistant infections as well. The response can also induce the transfer of mobile genetic elements, such as has been noted for SXT, an integrating conjugating element, in Vibrio cholerae allowing for the transfer of the multidrug resistance genes. ${ }^{99}$ Furthermore, in a study with Staphylococcus aureus, antibiotics induced the SOS response, which in turn activated the transduction of virulence genes. ${ }^{100}$ This suggests that infection with transducing phages leads to more virulent pathogenic bacteria that are resistant to antibiotics.

It has long been believed that antibiotic-resistant bacterial cells have reduced fitness compared to their susceptible counterparts and that, in the absence of antibiotic selection, populations of antibiotic resistant strains will decrease, but, unfortunately, there is no solid evidence for this. ${ }^{101}$ It is now known that metabolic cost of antibiotic resistance is not as high as once believed and that cells, through continued selection and evolution, are able to mitigate that cost. ${ }^{101}$ Some cells do revert back to their previously susceptible state, but most cells will evolve compensatory mutations. ${ }^{101}$ For example, a study with Salmonella typhimurium and nalidixic acid resistance, showed a compensatory mutation in gyr $A$ that improves the fitness of the resistant strain. ${ }^{102}$ Not all antibiotic-resistance genes carry with them an associated fitness cost. Another study with $S$. typhimurium, demonstrated that about half of their fluoroquinolone-resistant isolates had a selective advantage over the sensitive parent strain in the absence of the antibiotic, indicating that this type of resistance is not associated with a reduction in fitness. ${ }^{103}$

An in vivo study in which Bacteroides strains were analyzed from fecal samples from human volunteers exposed to clindamycin showed that within 7 days they had acquired erm genes (for erythromycin resistance) through conjugation and were resistant to clindamycin. This pattern continued through at least 18 months after the initial antibiotic administration suggesting that any fitness cost was quickly compensated. ${ }^{104}$ Another similar study from the same research group found that resistant populations of Bacteroides persisted at least 2 years after antibiotic administration. ${ }^{105}$ Resistant Staphylococcus epidermidis have been found 4 years after antibiotic treatment and resistant Enterococcus after 3 years. ${ }^{106,107}$ These and other studies suggest that even with the reduced usage or absence of antibiotics that antibiotic resistance determinants can be stably maintained in the bacterial population. ${ }^{108}$

\section{Conclusion}

Horizontal gene transfer in the gastrointestinal tract is of particular importance since antibiotic resistance genes can be acquired through transient bacteria or generated through mutations or rearrangements in a variety of elements in this environment. The intestinal microflora is a potential source of antibiotic resistant pathogen. These pathogens can cause infections via the fecal-oral route or through nosocomial infections such as bacteremia, endocarditis, urinary tract infections, and contamination of surgical sites.

The human gastrointestinal tract is a reservoir of enormous species diversity and density as well as a reservoir for hundreds to thousands of known antibiotic resistance genes with the mechanisms in place to horizontally transfer any gene. The capability of emergence of resistant pathogens from this habitat is astounding. The cure for the crisis of antibiotic resistance will not be as simple as encouraging and implementing the judicious use of antibiotics in agriculture and medicine, since resistant strains are very well adapted to growth. It is still unknown how long it will take 
and if ever resistance gene determinants will be lost from the populations of trillions of bacterial cells that reside in human gastrointestinal tracts worldwide.

\section{Acknowledgments}

Work on horizontal gene transfer in the author's laboratory has been supported by Pursuit Research Grants, MathScience Grants, and Undergraduate Research Grants at Abilene Christian University.

\section{Disclosure}

The author reports no conflicts of interest in this work.

\section{References}

1. Levy SB, Marshall B. Antibacterial resistance worldwide: causes, challenges and responses. Nat Med. 2004;10(Suppl 12):S122-S129.

2. de Kraker MEA, Davey PG, Grundmann H; BURDEN study group. Mortality and hospital stay associated with resistant Staphylococcus aureus and Escherichia coli bacteremia: estimating the burden of antibiotic resistance in Europe. PLoS Med. 2011;8(10):e1001104.

3. Armstrong GL, Conn LA, Pinner RW. Trends in infectious disease mortality in the United States during the 20th century. JAMA. 1999; 281(1):61-66.

4. Spellberg B, Powers JH, Brass EP, Miller LG, Edwards JE Jr. Trends in antimicrobial drug development: Implications for the future. Clin Infect Dis. 2004;38(9):1279-1286.

5. Arutyunov D, Frost LS. F conjugation: back to the beginning. Plasmid. 2013;70(1):18-32.

6. Smillie C, Garcillán-Barcia MP, Francia MV, Rocha EPC, de la Cruz F. Mobility of plasmids. Microbiol Mol Biol Rev MMBR. 2010;74(3): 434-452.

7. Zechner EL, Lang S, Schildbach JF. Assembly and mechanisms of bacterial type IV secretion machines. Philos Trans $R$ Soc B Biol Sci. 2012;367(1592):1073-1087.

8. Bacon DJ, Alm RA, Burr DH, et al. Involvement of a plasmid in virulence of Campylobacter jejuni 81-176. Infect Immun. 2000;68(8):4384-4390.

9. Waldor MK, Tschape H, Mekalanos JJ. A new type of conjugative transposon encodes resistance to sulfamethoxazole, trimethoprim, and streptomycin in Vibrio cholerae O139. J Bacteriol. 1996;178(14): $4157-4165$.

10. Zechner EL, de la Cruz F, Eisenbrandt R, et al. Conjugative-DNA transfer processes. In: Thomas CM, ed. Horizontal Gene Pool: Bacterial Plasmids and Gene Spread. CRC Press; 2003:87-174.

11. Guglielmini J, de la Cruz F, Rocha EP. Evolution of conjugation and type IV secretion systems. Mol Biol Evol. 2013;30(2):315-331.

12. Salyers AA, Shoemaker NB, Stevens AM, Li LY. Conjugative transposons: an unusual and diverse set of integrated gene transfer elements. Microbiol Rev. 1995;59(4):579-590.

13. Walsh TR. Combinatorial genetic evolution of multiresistance. Curr Opin Microbiol. 2006;9(5):476-482.

14. Hall RM. Integrons and gene cassettes: hotspots of diversity in bacterial genomes: Hall. Ann N Y Acad Sci. 2012;1267(1):71-78.

15. Beaber JW, Hochhut B, Waldor MK. Genomic and functional analyses of SXT, an integrating antibiotic resistance gene transfer element derived from Vibrio cholerae. J Bacteriol. 2002;184(15): 4259-4269.

16. Davies J, Davies D. Origins and evolution of antibiotic resistance. Microbiol Mol Biol Rev MMBR. 2010;74(3):417-433.

17. Norman A, Hansen LH, Sorensen SJ. Conjugative plasmids: vessels of the communal gene pool. Philos Trans R Soc B Biol Sci. 2009; 364(1527):2275-2289.
18. Lorenz MG, Wackernagel W. Bacterial gene transfer by natural genetic transformation in the environment. Microbiol Rev. 1994;58(3): $563-602$.

19. Johnston C, Martin B, Fichant G, Polard P, Claverys J-P. Bacterial transformation: distribution, shared mechanisms and divergent control. Nat Rev Microbiol. 2014;12(3):181-196.

20. Johnsborg O, Eldholm V, Håvarstein LS. Natural genetic transformation: prevalence, mechanisms and function. Res Microbiol. 2007;158(10):767-778.

21. Sparling PF. Genetic transformation of Neisseria gonorrhoeae to streptomycin resistance. J Bacteriol. 1966;92(5):1364-1371.

22. Finkel SE, Kolter R. DNA as a nutrient: Novel role for bacterial competence gene homologs. J Bacteriol. 2001;183(21):6288-6293.

23. Redfield RJ. Genes for breakfast: the have-your-cake-and-eat-it-too of bacterial transformation. J Hered. 1993;84(5):400-404.

24. Kristensen BM, Sinha S, Boyce JD, Bojesen AM, Mell JC, Redfield RJ. Natural transformation of Gallibacterium anatis. Appl Environ Microbiol. 2012;78(14):4914-4922.

25. Chandler MS. The gene encoding cAMP receptor protein is required for competence development in Haemophilus influenzae Rd. Proc Natl Acad Sci U S A. 1992;89(5):1626-1630.

26. Huddleston JR, Brokaw JM, Zak JC, Jeter RM. Natural transformation as a mechanism of horizontal gene transfer among environmental Aeromonas species. Syst Appl Microbiol. 2013;36(4): 224-234.

27. Sinha S, Mell J, Redfield R. The availability of purine nucleotides regulates natural competence by controlling translation of the competence activator Sxy. Mol Microbiol. 2013;88(6):1106-1119.

28. Michod RE, Wojciechowski MF, Hoelzer MA. DNA repair and the evolution of transformation in the bacterium Bacillus subtilis. Genetics. 1988;118(1):31-39.

29. Prudhomme M, Attaiech L, Sanchez G, Martin B, Claverys J-P. Antibiotic stress induces genetic transformability in the human pathogen Streptococcus pneumoniae. Science. 2006;313(5783):89-92.

30. Vos M. Why do bacteria engage in homologous recombination? Trends Microbiol. 2009;17(6):226-232.

31. Bacher JM, Metzgar D, Crécy-Lagard V de. Rapid evolution of diminished transformability in Acinetobacter baylyi. J Bacteriol. 2006;188(24):8534-8542.

32. Engelstädter J, Moradigaravand D. Adaptation through genetic time travel? Fluctuating selection can drive the evolution of bacterial transformation. Proc Biol Sci. 2014;281(1775):20132609.

33. Johnsen PJ, Dubnau D, Levin BR. Episodic selection and the maintenance of competence and natural transformation in Bacillus subtilis. Genetics. 2009;181(4):1521-1533.

34. Haijema BJ, Hahn J, Haynes J, Dubnau D. A ComGA-dependent checkpoint limits growth during the escape from competence. Mol Microbiol. 2001;40(1):52-64.

35. Bigger J. Treatment of staphylococcal infections with penicillin by intermittent sterilisation I. The Lancet. 1944;244(6320):497-500.

36. Lewis K. Persister cells, dormancy and infectious disease. Nat Rev Microbiol. 2007;5(1):48-56.

37. Bakkali M. Could DNA uptake be a side effect of bacterial adhesion and twitching motility? Arch Microbiol. 2013;195(4):279-289.

38. Averhoff B. DNA transport and natural transformation in mesophilic and thermophilic bacteria. J Bioenerg Biomembr. 2004;36(1): $25-33$.

39. Chen I, Dubnau D. DNA transport during transformation. Front Biosci J Virtual Libr. 2003;8:s544-s556.

40. Beiko RG, Harlow TJ, Ragan MA. Highways of gene sharing in prokaryotes. Proc Natl Acad Sci U S A. 2005;102(40):14332-14337.

41. Fortier L-C, Sekulovic O. Importance of prophages to evolution and virulence of bacterial pathogens. Virulence. 2013;4(5):354-365.

42. Muniesa M, Colomer-Lluch M, Jofre J. Could bacteriophages transfer antibiotic resistance genes from environmental bacteria to humanbody associated bacterial populations? Mob Genet Elem. 2013;3(4): e25847. 
43. Schmieger H, Schicklmaier P. Transduction of multiple drug resistance of Salmonella enterica serovar typhimurium DT104. FEMS Microbiol Lett. 1999;170(1):251-256.

44. Mann BA, Slauch JM. Transduction of low-copy number plasmids by bacteriophage P22. Genetics. 1997;146(2):447-456.

45. Dinsdale EA, Edwards RA, Hall D, et al. Functional metagenomic profiling of nine biomes. Nature. 2008;452(7187):629-632.

46. Mazaheri Nezhad Fard R, Barton MD, Heuzenroeder MW. Bacteriophage-mediated transduction of antibiotic resistance in enterococci: Transduction in Enterococcus spp. Lett Appl Microbiol. 2011;52(6):559-564.

47. Whitman WB, Coleman DC, Wiebe WJ. Prokaryotes: The unseen majority. Proc Natl Acad Sci U S A. 1998;95(12):6578-6583.

48. Eckburg PB, Bik EM, Bernstein CN, et al. Diversity of the human intestinal microbial flora. Science. 2005;308(5728):1635-1638.

49. Ley RE, Peterson DA, Gordon JI. Ecological and evolutionary forces shaping microbial diversity in the human intestine. Cell. 2006;124(4): 837-848.

50. Sørensen SJ, Bailey M, Hansen LH, Kroer N, Wuertz S. Studying plasmid horizontal transfer in situ: a critical review. Nat Rev Microbiol. 2005;3(9):700-710.

51. Licht TR, Christensen BB, Krogfelt KA, Molin S. Plasmid transfer in the animal intestine and other dynamic bacterial populations: the role of community structure and environment. Microbiology. 1999;145(9):2615-2622.

52. Krogfelt KA, Poulsen LK, Molin S. Identification of coccoid Escherichia coli BJ4 cells in the large intestine of streptomycin-treated mice. Infect Immun. 1993;61(12):5029-5034.

53. Poulsen LK, Lan F, Kristensen CS, Hobolth P, Molin S, Krogfelt KA. Spatial distribution of Escherichia coli in the mouse large intestine inferred from rRNA in situ hybridization. Infect Immun. 1994;62(11): 5191-5194.

54. Marks LR, Mashburn-Warren L, Federle MJ, Hakansson AP. Streptococcus pyogenes biofilm growth in vitro and in vivo and its role in colonization, virulence and genetic exchange. J Infect Dis. 2014: Epub January 23, 2014.

55. Mills S, Shanahan F, Stanton C, Hill C, Coffey A, Ross RP. Movers and shakers. Gut Microbes. 2013;4(1):4-16.

56. Anwar H, Dasgupta MK, Costerton JW. Testing the susceptibility of bacteria in biofilms to antibacterial agents. Antimicrob Agents Chemother. 1990;34(11):2043-2046.

57. Salyers AA, Gupta A, Wang Y. Human intestinal bacteria as reservoirs for antibiotic resistance genes. Trends Microbiol. 2004;12(9): 412-416.

58. Liu B, Pop M. ARDB - Antibiotic Resistance Genes Database. Nucleic Acids Res. 2009;37(suppl 1):D443-D447.

59. Ghosh TS, Gupta SS, Nair GB, Mande SS. In silico analysis of antibiotic resistance genes in the gut microflora of individuals from diverse geographies and age-groups. PLoS ONE. 2013;8(12):e83823.

60. Sommer MOA, Dantas G, Church GM. Functional characterization of the antibiotic resistance reservoir in the human microflora. Science. 2009;325(5944):1128-1131.

61. Hu Y, Yang X, Qin J, et al. Metagenome-wide analysis of antibiotic resistance genes in a large cohort of human gut microbiota. Nat Commun. $2013 ; 4: 2151$

62. Forslund K, Sunagawa S, Kultima JR, et al. Country-specific antibiotic use practices impact the human gut resistome. Genome Res. 2013;23(7): 1163-1169.

63. Marshall BM, Levy SB. Food animals and antimicrobials: impacts on human health. Clin Microbiol Rev. 2011;24(4):718-733.

64. Schjorring, Susanne, Krogfelt KA. Assessment of bacterial antibiotic resistance transfer in the gut. Int J Microbiol. 2011;2011:1-10.

65. Carr FJ, Chill D, Maida N. The lactic acid bacteria: A literature survey. Crit Rev Microbiol. 2002;28(4):281.

66. Ammor MS, Flórez AB, Mayo B. Antibiotic resistance in nonenterococcal lactic acid bacteria and bifidobacteria. Food Microbiol. 2007;24(6):559-570.
67. Perreten V, Schwarz F, Cresta L, Boeglin M, Dasen G, Teuber M. Antibiotic resistance spread in food. Nature. 1997;389(6653):801-802.

68. Egervärn M, Lindmark H, Olsson J, Roos S. Transferability of a tetracycline resistance gene from probiotic Lactobacillus reuteri to bacteria in the gastrointestinal tract of humans. Antonie Van Leeuwenhoek. 2010;97(2):189-200.

69. Drago L, Rodighiero V, Mattina R, Toscano M, DE Vecchi E. In vitro selection and transferability of antibiotic resistance in the probiotic strain Lactobacillus reuteri DSM 17938. J Chemother Florence Italy. 2011;23(6):371-373.

70. Lester CH, Frimodt-Møller N, Sørensen TL, Monnet DL, Hammerum AM. In vivo transfer of the vanA resistance gene from an Enterococcus faecium isolate of animal origin to an E. faecium isolate of human origin in the intestines of human volunteers. Antimicrob Agents Chemother. 2006;50(2):596-599.

71. Trobos M, Lester CH, Olsen JE, Frimodt-Møller N, Hammerum AM. Natural transfer of sulphonamide and ampicillin resistance between Escherichia coli residing in the human intestine. J Antimicrob Chemother. 2009;63(1):80-86.

72. Crémet L, Bourigault C, Lepelletier D, et al. Nosocomial outbreak of carbapenem-resistant Enterobacter cloacae highlighting the interspecies transferability of the bla $a_{\text {OXA-48 }}$ gene in the gut flora. J Antimicrob Chemother. 2012;67(4):1041-1043.

73. Karami N, Martner A, Enne VI, Swerkersson S, Adlerberth I, Wold AE. Transfer of an ampicillin resistance gene between two Escherichia coli strains in the bowel microbiota of an infant treated with antibiotics. J Antimicrob Chemother. 2007;60(5):1142-1145.

74. Goren MG, Carmeli Y, Schwaber MJ, Chmelnitsky I, Schechner V, Navon-Venezia S. Transfer of carbapenem-resistant plasmid from Klebsiella pneumoniae ST258 to Escherichia coli in patient. Emerg Infect Dis. 2010;16(6):1014-1017.

75. Duval-Iflah Y, Raibaud P, Tancrede C, Rousseau M. R-plasmic transfer from Serratia liquefaciens to Escherichia coli in vitro and in vivo in the digestive tract of gnotobiotic mice associated with human fecal flora. Infect Immun. 1980;28(3):981-990.

76. Sparo M, Urbizu L, Solana MV, et al. High-level resistance to gentamicin: genetic transfer between Enterococcus faecalis isolated from food of animal origin and human microbiota. Lett Appl Microbiol. 2012;54(2):119-125.

77. Lester CH, Frimodt-Moller N, Hammerum AM. Conjugal transfer of aminoglycoside and macrolide resistance between Enterococcus faecium isolates in the intestine of streptomycin-treated mice. FEMS Microbiol Lett. 2004;235(2):385-391.

78. Carattoli A. Resistance plasmid families in Enterobacteriaceae. Antimicrob Agents Chemother. 2009;53(6):2227-2238.

79. Khajuria A, Praharaj AK, Kumar M, Grover N, Aggarwal A. Multidrug resistant NDM-1 metallo-beta-lactamase producing Klebsiella pneumoniae sepsis outbreak in a neonatal intensive care unit in a tertiary care center at central India. Indian J Pathol Microbiol. 2014;57(1): 65-68.

80. Schlüter A, Nordmann P, Bonnin RA, et al. IncH-type plasmid harboring the $b l a_{\text {СтХ-м-15 }}, b l a_{\mathrm{DHA}-1}$, and $q n r \mathrm{~B} 4$ genes recovered from animal isolates. Antimicrob Agents Chemother. 2014.

81. Marchaim D, Chopra T, Pogue JM, et al. Outbreak of colistin-resistant, carbapenem-resistant Klebsiella pneumoniae in Metropolitan Detroit, Michigan. Antimicrob Agents Chemother. 2011;55(2):593-599. [Epub ahead of print].

82. Long KS, Poehlsgaard J, Kehrenberg C, Schwarz S, Vester B. The Cfr rRNA methyltransferase confers resistance to phenicols, lincosamides, oxazolidinones, pleuromutilins, and streptogramin A antibiotics. Antimicrob Agents Chemother. 2006;50(7):2500-2505.

83. De Vries LE, Vallès Y, Agersø Y, et al. The gut as reservoir of antibiotic resistance: Microbial diversity of tetracycline resistance in mother and infant. PLoS ONE. 2011;6(6):e21644.

84. Shoemaker NB, Vlamakis H, Hayes K, Salyers AA. Evidence for extensive resistance gene transfer among Bacteroides spp. and among Bacteroides and other genera in the human colon. Appl Environ Microbiol. 2001;67(2):561-568. 
85. Radman M. SOS repair hypothesis: phenomenology of an inducible DNA repair which is accompanied by mutagenesis. Basic Life Sci. 1975;5A:355-367.

86. Michel B. After 30 years of study, the bacterial SOS response still surprises us. PLoS Biol. 2005;3(7):e255.

87. Varhimo E, Savijoki K, Jefremoff H, Jalava J, Sukura A, Varmanen P. Ciprofloxacin induces mutagenesis to antibiotic resistance independent of UmuC in Streptococcus uberis. Environ Microbiol. 2008;10(8): 2179-2183.

88. Alonso A, Campanario E, Martinez JL. Emergence of multidrugresistant mutants is increased under antibiotic selective pressure in Pseudomonas aeruginosa. Microbiology. 1999;145(10):2857-2862.

89. Kim J, Noh J, Park W. Insight into norfloxacin resistance of Acinetobacter oleivorans DR1: target gene mutation, persister, and RNA-Seq analyses. J Microbiol Biotechnol. 2013;23(9):1293-1303.

90. Charpentier X, Kay E, Schneider D, Shuman HA. Antibiotics and UV radiation induce competence for natural transformation in Legionella pneumophila. J Bacteriol. 2011;193(5):1114-1121.

91. Whitchurch CB, Tolker-Nielsen T, Ragas PC, Mattick JS. Extracellular DNA required for bacterial biofilm formation. Science. 2002;295(5559):1487.

92. Charpentier X, Polard P, Claverys J-P. Induction of competence for genetic transformation by antibiotics: convergent evolution of stress responses in distant bacterial species lacking SOS? Curr Opin Microbiol. 2012;15(5):570-576.

93. Lemire S, Figueroa-Bossi N, Bossi L. Bacteriophage crosstalk: Coordination of prophage induction by trans-acting antirepressors. PLoS Genet. 2011;7(6):e1002149.

94. Ulrich RL, Deshazer D, Kenny TA, et al. Characterization of the Burkholderia thailandensis SOS response by using wholetranscriptome shotgun sequencing. Appl Environ Microbiol. 2013;79(19): 5830-5843.

95. Modi SR, Lee HH, Spina CS, Collins JJ. Antibiotic treatment expands the resistance reservoir and ecological network of the phage metagenome. Nature. 2013;499(7457):219-222.

96. Collins SM, Denou E, Verdu EF, Bercik P. The putative role of the intestinal microbiota in the irritable bowel syndrome. Dig Liver Dis OffJ Ital Soc Gastroenterol Ital Assoc Study Liver. 2009;41(12):850-853.
97. Reiff C, Kelly D. Inflammatory bowel disease, gut bacteria and probiotic therapy. Int J Med Microbiol IJMM. 2010;300(1):25-33.

98. Wagner J, Maksimovic J, Farries G, et al. Bacteriophages in gut samples from pediatric Crohn's disease patients: metagenomic analysis using 454 pyrosequencing. Inflamm Bowel Dis. 2013;19(8):1598-1608.

99. Beaber JW, Hochhut B, Waldor MK. SOS response promotes horizontal dissemination of antibiotic resistance genes. Nature. 2004;427(6969):72-74.

100. Úbeda C, Maiques E, Knecht E, Lasa Í, Novick RP, Penadés JR. Antibiotic-induced SOS response promotes horizontal dissemination of pathogenicity island-encoded virulence factors in staphylococci: Horizontal dissemination of virulence genes. Mol Microbiol. 2005;56(3):836-844.

101. Andersson DI, Levin BR. The biological cost of antibiotic resistance. Curr Opin Microbiol. 1999;2(5):489-493.

102. Bjorkman J, Hughes D, Andersson DI. Virulence of antibiotic-resistant Salmonella typhimurium. Proc Natl Acad Sci U S A. 1998;95(7): 3949-3953.

103. Baker S, Duy PT, Nga TVT, et al. Fitness benefits in fluoroquinoloneresistant Salmonella typhi in the absence of antimicrobial pressure. eLife. 2013;2.

104. Löfmark S, Jernberg C, Billström H, Andersson DI, Edlund C. Restored fitness leads to long-term persistence of resistant Bacteroides strains in the human intestine. Anaerobe. 2008;14(3):157-160.

105. Jernberg C, Löfmark S, Edlund C, Jansson JK. Long-term ecological impacts of antibiotic administration on the human intestinal microbiota. ISME J. 2007;1(1):56-66.

106. Sjölund M, Tano E, Blaser MJ, Andersson DI, Engstrand L. Persistence of resistant Staphylococcus epidermidis after single course of clarithromycin. Emerg Infect Dis. 2005;11(9):1389-1393.

107. Sjölund M, Wreiber K, Andersson DI, Blaser MJ, Engstrand L. Long-term persistence of resistant Enterococcus species after antibiotics to eradicate Helicobacter pylori. Ann Intern Med. 2003;139(6): 483-487.

108. Jakobsson HE, Jernberg C, Andersson AF, Sjölund-Karlsson M, Jansson JK, Engstrand L. Short-term antibiotic treatment has differing long-term impacts on the human throat and gut microbiome. PloS One. 2010;5(3):e9836.
Infection and Drug Resistance

\section{Publish your work in this journal}

Infection and Drug Resistance is an international, peer-reviewed openaccess journal that focuses on the optimal treatment of infection (bacterial, fungal and viral) and the development and institution of preventive strategies to minimize the development and spread of resistance. The journal is specifically concerned with the epidemiology of antibiotic

\section{Dovepress}

resistance and the mechanisms of resistance development and diffusion in both hospitals and the community. The manuscript management system is completely online and includes a very quick and fair peerreview system, which is all easy to use. Visit http://www.dovepress.com/ testimonials.php to read real quotes from published authors. 